\title{
Unravelling the Photocatalytic Behavior of All-Inorganic Mixed Halide Perovskites: The Role of Surface Chemical States
}

Andrés. F. Gualdrón-Reyes ${ }^{\# 1,2 *}$ Jhonatan Rodríguez-Pereira, ${ }^{\#, 3}$ Eliseo Amado-González, ${ }^{1}$ Jorge Rueda-P, ${ }^{4}$ Rogelio Ospina, ${ }^{3}$ Sofía Masi, ${ }^{2}$ Seog Joon Yoon, ${ }^{2,5}$ Juan Tirado, ${ }^{6}$ Franklin Jaramillo, ${ }^{6}$ Said Agouram, ${ }^{7,8}$ Vicente Muñoz-Sanjosé, ${ }^{7,8}$ Sixto Giménez, ${ }^{2,8}$ and Iván Mora-Seró ${ }^{2,8 *}$

${ }^{1}$ Biofuels Lab-IBEAR, Faculty of Basic Sciences, University of Pamplona, Pamplona, Colombia. C. P. 543050 .

${ }^{2}$ Institute of Advanced Materials (INAM), Universitat Jaume I (UJI), Avenida de Vicent Sos Baynat, s/n, 12006 Castelló de la Plana, Castellón, Spain.

${ }^{3}$ Centro de Investigación Científica y Tecnológica en Materiales y Nanociencias (CMN), Universidad Industrial de Santander, Piedecuesta, Santander, Colombia. C.P. 681011.

${ }^{4}$ Modern Optic Group, Faculty of Basic Sciences, University of Pamplona, Pamplona, Colombia. C. P. 543050 .

${ }^{5}$ Department of Chemistry, College of Natural Science, Yeungnam University, 280 Daehak-Ro, Gyeongsan, Gyeongbuk 38541, Republic of Korea.

${ }^{6}$ Centro de Investigación, Innovación y Desarrollo de Materiales CIDEMAT, Universidad de Antioquia UdeA, Calle 70 No. 52-21, Medellín, Colombia.

${ }^{7}$ Department of Applied Physics and Electromagnetism, University of Valencia (UV), 46100 Valencia, Spain.

${ }^{8}$ Unitat Mixta d'Investigació UV-UJI, Materials for Renewable Energy (MAER), Spain.

*Corresponding author: gualdron@uji.es, sero@uji.es

\#: equal contribution 


\begin{abstract}
Within the most mesmerizing materials in the world of optoelectronics, mixed halide perovskites (MHP) have been distinguished due to the tunability of their optoelectronic properties, balancing both the light harvesting efficiency and charge extraction into highly efficient solar devices. This feature has drawn the attention of analogous hot-topics as photocatalysis for carrying out more efficiently the degradation of organic compounds. However, the photo-oxidation ability of perovskite does not only depend on its excellent light-harvesting properties, but also on the surface chemical environment provided during its synthesis. Accordingly, we studied the role of surface chemical states of MHP based nanocrystals (NCs) synthesized by hot-injection (H-I) and anion-exchange (A-E) approaches, on their photocatalytic (PC) activity for the oxidation of $\beta$-naphthol as a model system. We concluded that iodide vacancies are the main surface chemical states that facilitate the formation of superoxide ions, $\mathrm{O}_{2}{ }^{\bullet-}$, responsible for the PC activity in A-E-MHP. Conversely, the PC performance of H-I-MHP is related to the appropriate balance between band gap and a highly oxidizing valence band. This work offers new insights on the surface properties of MHP related to their catalytic activity in photochemical applications.
\end{abstract}

Keywords: Surface chemical states, iodide vacancies, hot-injection, anion-exchange, superoxide ions, photocatalytic activity, degradation pathways,

\title{
1. Introduction
}

All-inorganic halide perovskites have become extremely competitive optoelectronic materials due to their high sunlight harvesting efficiency and notable charge carrier generation/transfer capabilities. ${ }^{1,2}$ These features have been recognized as the key factors for enhancing photoconversion efficiencies in solar photovoltaic devices. ${ }^{3}$ Furthermore, their fascinating photoluminescence quantum yield (PLQY), induced by a low nonradiative carrier recombination effect, can explain the expansion of their applicability in the wide optoelectronic field. ${ }^{4} \mathrm{~A}$ high and prolonged PLQY from halide perovskites is the indication of the defect-tolerant structure, which increases the lifetime of photoexcited charge carriers. ${ }^{5}$ This feature has been successfully exploited in few works related with photocatalysis, for increasing the oxidizing power during the photodegradation of organic molecules. ${ }^{6-8}$ Pure perovskite nanocrystals (NCs) such as $\mathrm{CsPbBr}_{3}$ and $\mathrm{CsPbI}_{3}$ exhibit fixed band gaps. ${ }^{9}$ By tuning the chemical composition of the NCs, harnessing band engineering approaches, both the light harvesting and relative positions of valence and conduction bands (VB and CB, respectively) are controlled. ${ }^{10,11}$ Therefore, the photo-oxidation and/or photo-reduction abilities of these materials can be maximized. The band engineering mediated by chemical composition has been useful to improve the photocatalytic (PC) properties of earth-abundant 
insulators such as $\mathrm{BaSO}_{4}$ by incorporating Ba-vacancies. ${ }^{12}$ Band gap of modified $\mathrm{BaSO}_{4}$ was reduced to improve its light harvesting efficiency, achieving a highly oxidizing VB, and performing more efficiently the PC removal of NO molecules. In this context, $\mathrm{CsPbBr}_{3-\mathrm{x}} \mathrm{I}_{\mathrm{x}}$ mixed halide perovskites (MHP) NCs constitute highly promising materials due to the improved light-to-carrier conversion efficiency with tunable band gap, which can be optimized by adjusting the halide content in their structure. ${ }^{9}$ This outstanding photophysical feature has been extremely useful for the fabrication of efficient optoelectronic devices as multijunction tandem solar cells ${ }^{13}$ and multicolor light-emitting diodes. ${ }^{14,15}$ Nevertheless, very few works have reported the use of $\mathrm{CsPbX}_{3} \mathrm{NCs}(\mathrm{X}=\mathrm{Br}$, I or Br/I combinations) for solar synthesis (e.g. polymerization of 3,4-ethylenedioxythiophene), ${ }^{16} \mathrm{CO}_{2}$ reduction to $\mathrm{C}_{1}$ products as methane and carbon monoxide, ${ }^{6,17}$ solar fuel generation (e.g. hydrogen production), ${ }^{18,19}$ and advanced oxidation processes. ${ }^{8,11}$

For the synthesis of MHP NCs, some methods have been described in the literature: (1) hot-injection (H-I), (2) anion-exchange (A-E), and supersaturated recrystallization (S-R) approaches. ${ }^{4,20,}{ }^{21} \mathrm{H}-\mathrm{I}$ is performed by pre-mixing certain amounts of lead bromide $\left(\mathrm{PbBr}_{2}\right)$ and iodide $\left(\mathrm{PbI}_{2}\right)$ salts. This fact ensures the complete reaction of both the precursors $\mathrm{PbBr}_{2} / \mathrm{PbI}_{2}$, predicting the right MHP stoichiometry. ${ }^{9}$ In $\mathrm{A}-\mathrm{E}$, pure $\mathrm{CsPbBr}_{3}$ and $\mathrm{CsPbI}_{3}$ colloidal NCs are mixed together with different $\mathrm{Br}: \mathrm{I}$ ratios, taking advantage of the high ion mobility of halides into the perovskite lattice. ${ }^{20,} 22$ In S-R, MHP NCs are obtained in the absence of inert gas and injection process. ${ }^{21}$ However, for A-E method halide diffusion generates inhomogeneous composition across the perovskite nanostructure, producing domains with high iodide content at the surface with a small bromide content within the core. ${ }^{5,23}$ Moreover, it has been observed that iodide vacancies are formed at the MHP surface, defined by the presence of metallic lead $\left(\mathrm{Pb}^{0}\right)$ detected by as X-ray photoelectron spectroscopy (XPS). The defect density tends to linearly increase with the amount of $\mathrm{CsPbI}_{3}$ in the A-E synthesis, ${ }^{5}$ facilitating the $\mathrm{O}_{2}$ incorporation, and consequently inducing the perovskite degradation. ${ }^{24,25}$

However, it is not clear whether $\mathrm{O}_{2}$ is really harmful for the performance of all solar-driven processes carried out by moisture-affected photoactive materials. The $\mathrm{O}_{2}$-diffused $\mathrm{CH}_{3} \mathrm{NH}_{3} \mathrm{PbI}_{3}$ layers produce highly reactive superoxide ions $\left(\mathrm{O}_{2}{ }^{\bullet-}\right)$ under illumination, trapping photoexcited electrons, which are otherwise transported in the solar cells. Although this fact is directly associated to the decrease of the photoconversion efficiencies in the solar devices, ${ }^{24,26}$ the $\mathrm{O}_{2}{ }^{--}$can act as an active intermediate species in reactions involving the degradation of organic molecules like cyanotoxins, ${ }^{27}$ quinolones ${ }^{28}$ and phenol derivates, ${ }^{29,30}$ among others. High reactive $\mathrm{O}_{2}{ }^{\bullet-}$ species have been also identified as the main factor for the PC performance of modified semiconductors such as $\mathrm{Bi}$ metal-deposited $\mathrm{Bi}_{2} \mathrm{GeO}_{5}$ to mediate an efficient NO oxidation, ${ }^{31}$ and metal-organic frameworks as UiO-67 to perform the plasma-assisted dry 
reforming of methane in order to obtain $\mathrm{CO}$ and $\mathrm{C}_{2} \mathrm{H}_{4} \cdot{ }^{32}$ Therefore, it is crucial to shine light on the effect of the highly reactive $\mathrm{O}_{2}{ }^{\bullet-}$ species formed at the MHP surface, for the efficient PC oxidation of organic compounds, well-known to be correlated to the chemical environment of the photocatalyst itself.

In this work, the surface chemical states present at MHP NCs synthesized by two different methods, $\mathrm{H}-\mathrm{I}$ and $\mathrm{A}-\mathrm{E}\left(\mathrm{H}-\mathrm{I}-\mathrm{CsPbBr}{ }_{3-\mathrm{x}} \mathrm{I}_{\mathrm{x}}\right.$ and $\mathrm{A}-\mathrm{E}-\mathrm{CsPbBr}{ }_{3-\mathrm{x}} \mathrm{I}_{\mathrm{x}}$ MHP, respectively) are correlated with the PC degradation efficiency of organic molecules, using as benchmark system the $\beta$-naphthol. By studying their optical properties, surface chemical environment, composition, and photo-oxidation ability, interestingly we demonstrate that the NCs synthesis process plays a very important role in the chemical reactions inducing the photodegradation, due to the different surface nature of the prepared NCs. The PC behavior of both H-I-MHP and A-E-MHP is dictated by two different degradation pathways. $\beta$-naphthol is mainly degraded via highly-oxidizing photoexcited VB holes by using H-I-MHP, while A-E-MHP oxidize the organic molecule through the reactive $\mathrm{O}_{2}{ }^{--}$species. The formation of these superoxide species is directly associated with the density of surface iodide vacancies at the MHP NCs. The presence of $\mathrm{O}_{2}{ }^{\bullet-}$ species promotes a concerted double proton-coupled electron transfer reaction, producing $\mathrm{H}_{2} \mathrm{O}_{2}$ as a byproduct. These findings constitute an important step forward on the understanding of the reactivity of MHP, opening the possibility to introduce these materials as novel catalysts for many different PC applications.

\section{Results and Discussions}

\subsection{Morphology and photophysical features of hot-injection and anion-exchange mixed halide perovskite} nanocrystals

Figures 1A-G show TEM images of colloidal H-I-MHP and A-E-MHP NCs and their corresponding luminescent colors. For all the materials, the typical cubic morphology was evidenced, achieving a particle size between 11.1 and $13.6 \mathrm{~nm}$. The size distribution of each MHP is shown as Figure S1A-G. The UV-Vis absorption onset of the MHP NCs (Figure 1H) was red-shifted after iodine incorporation in $\mathrm{H}-\mathrm{I}-\mathrm{CsPbBr}_{3-\mathrm{x}} \mathrm{I}_{\mathrm{x}}$ and $\mathrm{A}-\mathrm{E}-\mathrm{CsPbBr}_{3-\mathrm{x}} \mathrm{I}_{\mathrm{x}}$, due to the lower band gap $\left(\mathrm{E}_{\mathrm{g}}\right)$. Consistently, the photoluminescence (PL) emission only exhibited a single symmetric peak, which was also red shifted (Figure S2B).The narrow full width at half maximum (FWHM) (Figure S2C), highlights that the preparation was effective to achieve homogeneous solid solutions with larger particle size for the iodine

enriched MHP. This fact is in good agreement with TEM images. ${ }^{4,9}$ From emission peak positions, the estimation of the $\mathrm{E}_{\mathrm{g}}$ values (Table S2), confirmed that H-I and A-E are suitable methods to modulate the band gap of NCs, thus covering a broad range of the visible spectra (from green to red). The influence of 
the halide content on the crystalline structure of the H-I-MHP and A-E-MHP was also assessed by XRD (Figure S2A), where two main diffraction peaks are present for all studied materials. These signals were ascribed to the (100) and (200) planes from the perovskite lattice, crystallizing in a pure single cubic phase (JCPDS card \# 00-054-0752). ${ }^{33}$ Furthermore, the two representative peak positions at the XRD profiles were shifted to lower Bragg angles after increasing the amount of iodine into the perovskite NCs. This fact was ascribed to the enlargement of the $\mathrm{Pb}-\mathrm{X}$ bond by increasing the ionic radius of the halide anion during bromine-to-iodine substitution. ${ }^{22,34}$ Through EDS analysis, the chemical compositions of $\mathrm{H}$ I-MHP and A-E-MHP were estimated (Table S1). It was observed that the stoichiometry of the $\mathrm{CsPbX}_{3^{-}}$ type structure in the NCs remained unaltered after variation of the halide content.

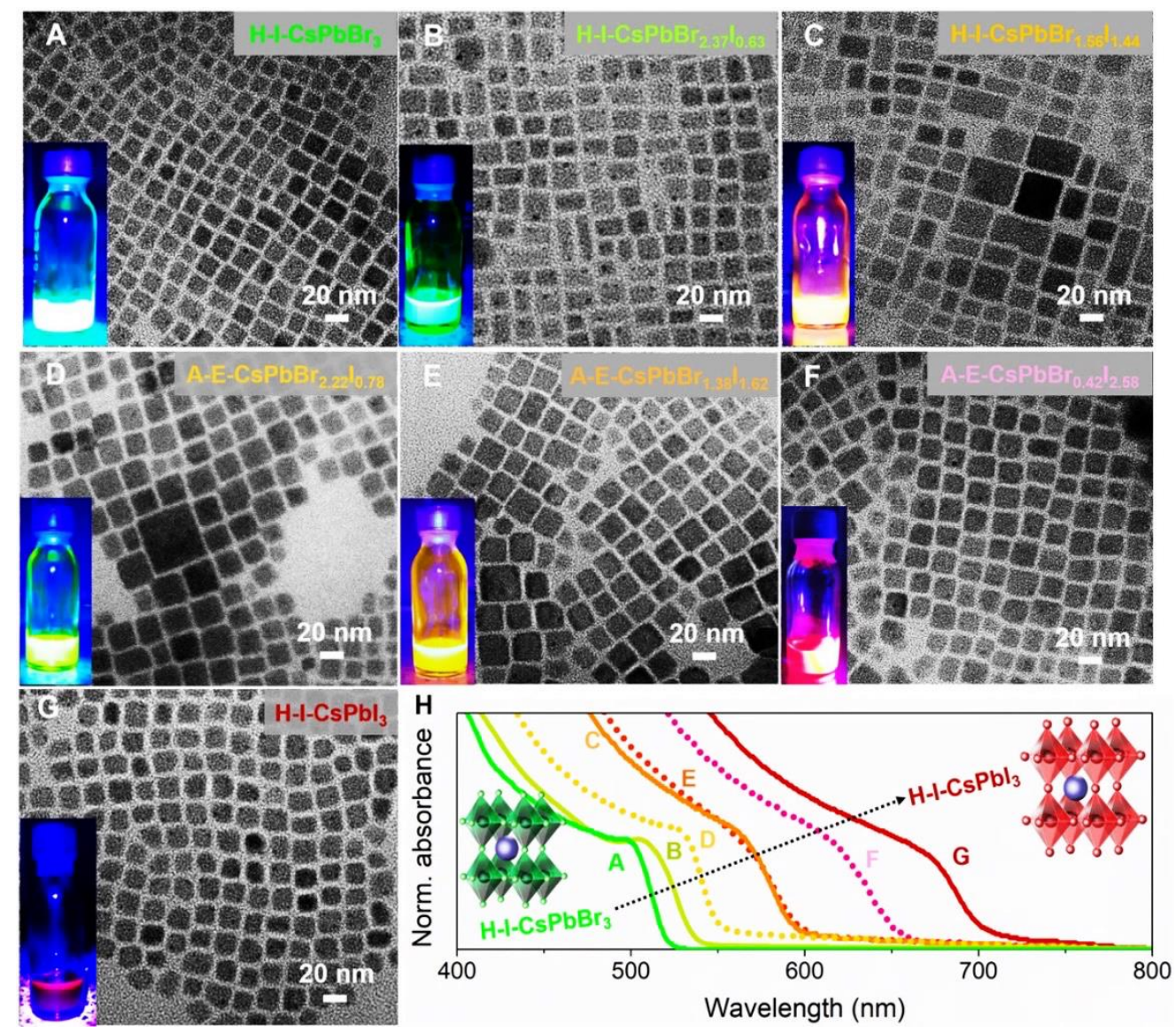

Figure 1. (A-G) TEM images and (H) UV-Vis spectra of $\mathrm{CsPbBr}_{3-\mathrm{x}} \mathrm{I}_{\mathrm{x}}$ mixed halide perovskite nanocrystals obtained by hot-injection (H-I) and anion-exchange (A-E) approaches. (H) UV-Vis absorbance spectra of the different solutions shown in (A-G), solid lines for H-I perovskites and dotted lines for A-E perovskites. 
In order to gain information about the kinetics of the halide exchange reactions between $\mathrm{CsPbBr}_{3}$ and $\mathrm{CsPbI}_{3} \mathrm{NC}$, we followed the reactions of the two precursors mixed in the three different ratios by steadystate PL spectroscopy during $30 \mathrm{~min}$. Time-dependent PL emission spectra are showed in Figures 2A-C. It has been proposed that this exchange process occurs by simultaneous halide migration between the perovskites (from bromide- to iodide-perovskite and vice-versa), ${ }^{22}$ however, our experiments did not show this behavior. In contrast, a decrease of the emission peak of the $\mathrm{CsPb}_{3} \mathrm{NCs}$ was observed upon iodine addition to the bromide perovskite to form $\mathrm{A}-\mathrm{E}-\mathrm{CsPbBr} \mathrm{Pb}_{2.22} \mathrm{I}_{0.78}$ and $\mathrm{A}-\mathrm{E}-\mathrm{CsPbBr}_{1.38} \mathrm{I}_{1.62}$ (Figures 2A,B). Additionally, an increase of the emission peak of the $\mathrm{CsPbr}_{3} \mathrm{NCs}$ was observed upon $\mathrm{Br}$ addition to the iodide perovskite to obtain $\mathrm{A}-\mathrm{E}-\mathrm{CsPbBr} \mathrm{.}_{2.2} \mathrm{I}_{2.58}$ (Figure $2 \mathrm{C}$ ). At the end of the reaction time, a single emission peak was observed for all the perovskite NCs combinations, indicating the formation of the fully exchanged A-E-CsPbBr 3 - $\mathrm{I}_{\mathrm{x}}$ MHP phases. ${ }^{35,36}$ This behavior is clearly related to the low activation energy for both bromide and iodide mobility $\left(\mathrm{Br}^{-}=0.17-0.25 \mathrm{eV}, \mathrm{I}^{-}=0.23-0.43 \mathrm{eV}\right),{ }^{37}$ and in particular, to the higher complexation affinity of the $\mathrm{Pb}-\mathrm{Br}$ bond compared to the $\mathrm{Pb}-\mathrm{I}$ bond. ${ }^{5,38}$ This fact leads to an faster diffusion of the iodide anions into the $\mathrm{CsPBr}_{3} \mathrm{NCs}$, compared to the diffusion of the bromide anions into the $\mathrm{CsPbI}_{3} \mathrm{NCs}$.

Therefore, the different migration kinetics between iodide and bromide causes inhomogeneity into the MHP structure. ${ }^{5}$ Moreover, by increasing the $\mathrm{I}: \mathrm{Br}$ ratio, more iodide species can migrate in the $\mathrm{CsPb}_{3} \rightarrow \mathrm{CsPbBr}_{3}$ direction compared to bromide anions in the reverse way. Consequently, a low amount of bromide anions can replace some iodide positions, producing a high density of iodide vacancies at the $\mathrm{NC}$ surface. In the case of H-I-MHP, we can infer that the stoichiometry of the involved precursors in the synthesis of $\mathrm{CsPbBr}_{3-\mathrm{x}} \mathrm{I}_{\mathrm{x}}$ generates well-defined bromide- and iodide-domain positions. Thus, the halide gradient in the NC surface and the possibility to form halide vacancies is reduced (Figures S3A,B). To corroborate this hypothesis, the photophysical features of both $\mathrm{H}-\mathrm{I}-\mathrm{CsPbBr} \mathrm{Pb}_{2.37} \mathrm{I}_{0.63}$ and A-E-CsPbBr $\mathrm{Pr}_{2.22} \mathrm{I}_{0.78}$ were followed through emission measurements immediately after the synthesis and 90 days after synthesis, stored under air atmosphere. The emission peak position of $\mathrm{H}-\mathrm{I}-\mathrm{Cs} \mathrm{PbBr}_{2.37} \mathrm{I}_{0.63}$ was blue-shifted around $4 \mathrm{~nm}$ keeping their coloration (Figure S4A,A'). This fact is a clear indication of the good stability of the H-I-MHP sample. Conversely, the peak of $\mathrm{A}-\mathrm{E}-\mathrm{Cs} \mathrm{PbBr}_{2.22} \mathrm{I}_{0.78}$ was displaced around $24 \mathrm{~nm}$, close to the emission feature of pure $\mathrm{CsPBr}_{3} \mathrm{NCs}$ (Figures S4B,B'). These results strongly suggest that A-EMHP exhibits more iodide vacancies exposed to the $\mathrm{O}_{2}$ molecules compared to H-I-MHP, which is the main reason for self-degradation. ${ }^{25,} 39,40$ However, the fact that the $\mathrm{A}-\mathrm{E}-\mathrm{CsPbBr}_{2.22} \mathrm{I}_{0.78}$ was still luminescent is an indication that the degradation of all-inorganic perovskite nanocrystals is slow at room conditions. In this context, if the iodide vacancies are found at the NC surface as mentioned above, these species would be the main surface chemical states dictating the reactivity of MHP. 

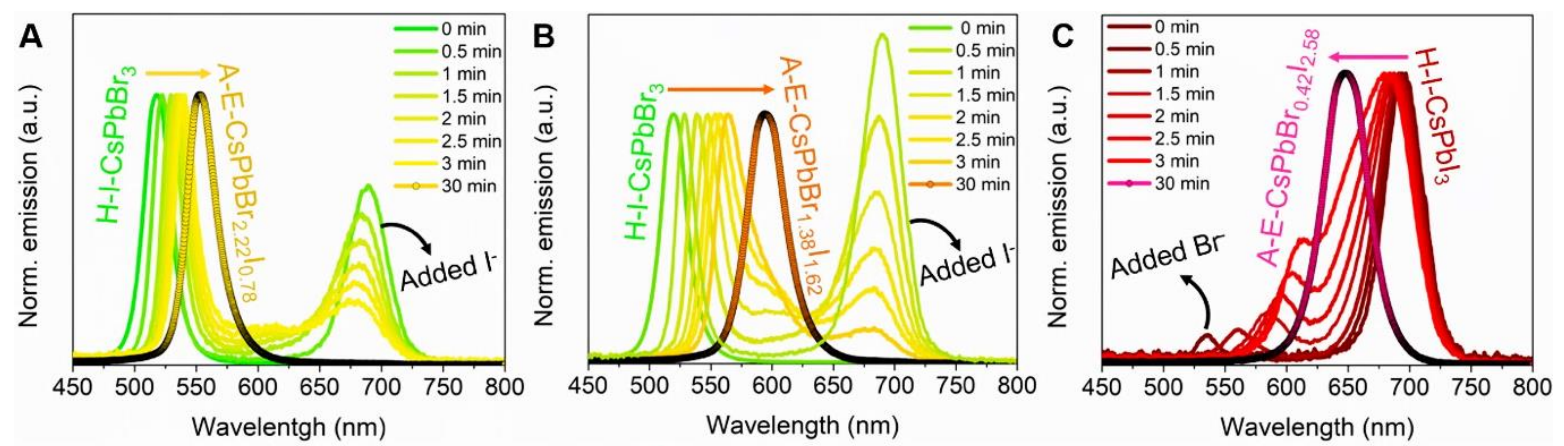

D
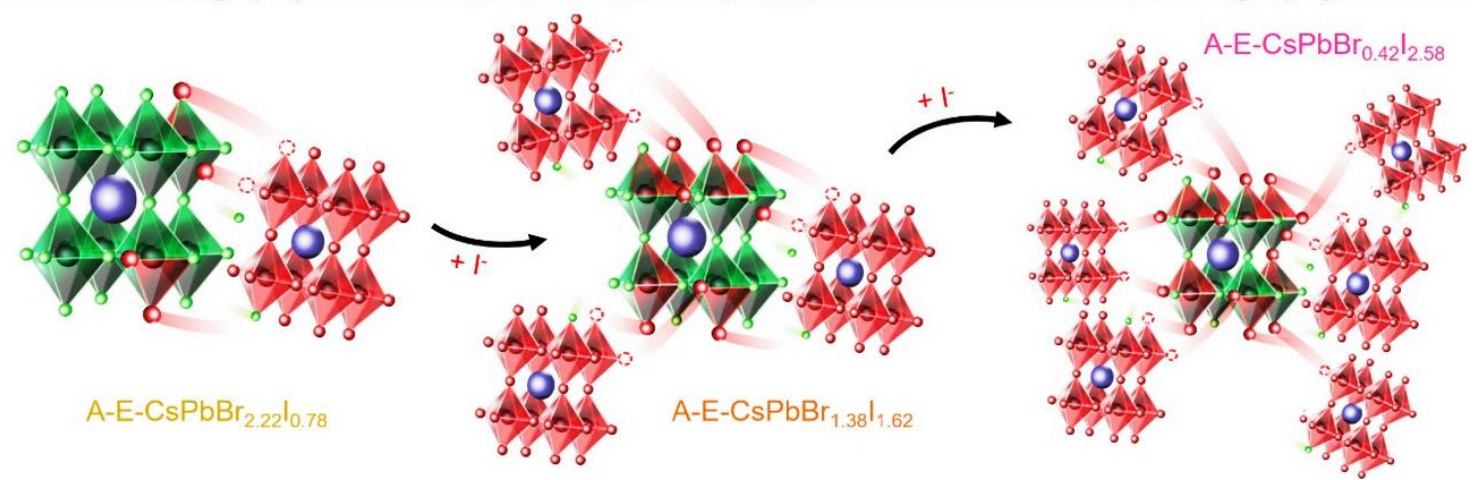

Figure 2. Time-dependent steady-state emission spectra under $405 \mathrm{~nm}$-continuous wave laser for anionexchange reactions between pure $\mathrm{H}-\mathrm{I}-\mathrm{Cs} \mathrm{PbBr}_{3}$ and $\mathrm{H}-\mathrm{I}-\mathrm{CsPbI}_{3}$ nanocrystals $\left(50 \mathrm{mg} \mathrm{mL}^{-1}\right.$ in hexane) using different Br:I volume ratios: (A) 3:1, (B) 1:1 and (C) 1:3. (D) Schematic representation of the halide exchange into A-E-CsPbBr ${ }_{3-\mathrm{x}} \mathrm{I}_{\mathrm{x}}$ to increase the iodide content.

Since PC reactions take place on the NC surface, ${ }^{11}$ it is essential to understand the nature and influence of surface chemical states on the PC activity of perovskite NCs, for further optimization of this photocatalytic system. In this context, X-ray Photoelectron Spectroscopy (XPS) allowed us to extract detailed information on the surface environment, composition and chemical species of both H-I-MHP and A-E-MHP NCs to determine the nature of these surface states. The survey spectra for all the materials are shown in Figures S5A,B, confirming the presence of $\mathrm{Cs}, \mathrm{Pb}, \mathrm{Br}$ and I. Figures 3A,A' show the HR-XPS Cs 3d spectra for the H-I-MHP and A-E-MHP NCs, where a representative doublet at 724.4/738.2 eV was obtained. These signals represent the Cs $3 \mathrm{~d}_{5 / 2}$ and Cs $3 \mathrm{~d}_{3 / 2}$ core levels, respectively, associated to the presence of $\mathrm{Cs}^{+}$into the $\mathrm{CsPbX}_{3}$-type structure. ${ }^{41}$ In addition, it was observed that the $\mathrm{Cs} 3 \mathrm{~d}$ doublet changes its binding energy (BE) depending on the type of perovskite. For H-I-MHP, these peaks were shifted to lower BEs by increasing the iodide content, which was ascribed to the substitution of $\mathrm{Br}^{-}$with $\mathrm{I}^{-}$ into the $\mathrm{Cs}-\left(\mathrm{PbX}_{6}\right)$ octahedra. ${ }^{42}$ Conversely, the opposite trend was evidenced for A-E-MHP, where the $\mathrm{BE}$ of $\mathrm{Cs} 3 \mathrm{~d}$ doublet was displaced to higher values by reducing the Br:I ratio. Here, the added $\mathrm{I}^{-}$content into $\mathrm{Cs}-\left(\mathrm{PbX}_{6}\right)$ octahedra was decreased after anion exchange. 
The effect of Br:I ratio on the halide substitution in MHP NCs was also studied on their corresponding high-resolution HR-XPS Br 3d (Figures 3B,B') and I 3d spectra (Figures 3C,C'). Typical doublets of $\mathrm{d}_{5 / 2}$ and $\mathrm{d}_{3 / 2}$ core levels were observed for both $\mathrm{Br}$ and $\mathrm{I} 3 \mathrm{~d}$ spectra, associated to $\mathrm{Pb}-\mathrm{Br}(68.0 / 69.1 \mathrm{eV})^{5,43}$ and $\mathrm{Pb}-\mathrm{I}(618.8 / 630.2 \mathrm{eV})^{44,45}$ bonds from the $\mathrm{CsPbBr}_{3-\mathrm{x}} \mathrm{I}_{\mathrm{x}}$ lattice. By comparing the $\mathrm{Br} 3 \mathrm{~d}$ doublets of H-IMHP and A-E-MHP with Br:I ratios 3:1 and 1:1, no changes in the BE were noted. This fact indicates the excellent stability of $\mathrm{Pb}-\mathrm{Br}$ into the $\mathrm{PbBr}_{6}$ octahedra. Nevertheless, a higher $\mathrm{BE}$ was recorded for the $\mathrm{Br}: \mathrm{I}$ ratio 1:3 during halide exchange process, suggesting the formation of some bromide vacancies into MHP. This could be possible if a high amount of iodide vacancies is formed at the NC surface to expose the bromide domain-based core. In order to corroborate this hypothesis, I 3d doublet analysis was carried out. Then, an increase of the iodide content in A-E-MHP to Br:I ratio 1:3 led to a shift to higher BE values. This trend nicely agreed with the chemical composition of each material (See Table 1), where the decrease of added $\mathrm{Br}^{-}$content as the Br:I ratio is decreased was clearly demonstrated. Here, the iodide content was almost constant suggesting that more iodide-deficient $\mathrm{PbI}_{6}$ octahedra were formed in A-EMHP. I 3d peaks for H-I-MHP red-shifted in the BE, confirming the incorporation of $\mathrm{I}^{-}$into the perovskite lattice. Consequently, there is a low possibility to produce halide-deficient domains. Therefore, we deduced that A-E-MHP contain a higher density of iodide vacancies compared to H-I-MHP. Moreover, for A-E-MHP NCs we observe a counterintuitive fact that the samples with the highest iodide content also present the highest iodide vacancy density concretely for the A-E-MHP with Br:I ratio 1:3 (A-E$\left.\mathrm{CsPbBr} 0 .{ }_{42} \mathrm{I}_{2.58}\right)$.

Figures 3D,D' exhibit the HR-XPS Pb 4f spectra for all the MHP NCs, where the two main peaks ascribed to $\mathrm{Pb} 4 \mathrm{f}_{7 / 2}$ and $\mathrm{Pb} 4 \mathrm{f}_{5 / 2}$ core levels were decomposed into two doublets. The first one at 137.8/142.7 eV corresponded to the presence of $\mathrm{Pb}^{2+}$ species originated from the $\mathrm{CsPbX}_{3}$ lattice. The second peak at 136.0/140.9 eV was associated to metallic lead $\left(\mathrm{Pb}^{0}\right)$ species formed due to the deficiency of iodide anions in the perovskites. ${ }^{45-47}$ Accordingly, it is expected that the decrease of the Br:I ratio for both H-I-MHP (from 3:1 to 1:1) and A-E-MHP NCs (from 3:1 to 1:3) rises the amount of $\mathrm{Pb}^{0}$. However, higher $\mathrm{Pb}^{0}$ content was quantified into the A-E-MHP NCs. This fact also corroborates that the anionexchange process produces more iodide vacancies into the MHP (Table 1). ${ }^{23}$ The lower complexation affinity between $\mathrm{Pb}^{2+}$ and $\mathrm{I}^{-}$compared to $\mathrm{Pb}^{2+}$ and $\mathrm{Br}^{-}$interaction, ${ }^{9,37,38}$ allows a faster iodide migration compared to bromide diffusion between $\mathrm{CsPbI}_{3}$ and $\mathrm{CsPbr}_{3}$ NCs. Hence, by increasing the iodide content in the A-E-MHP, more I' species are available to diffuse into NCs, and in turn highly iodide deficient MHP are generated. Therefore, at this stage, we can claim that iodide vacancies constitute the main surface chemical states produced in the MHP. 

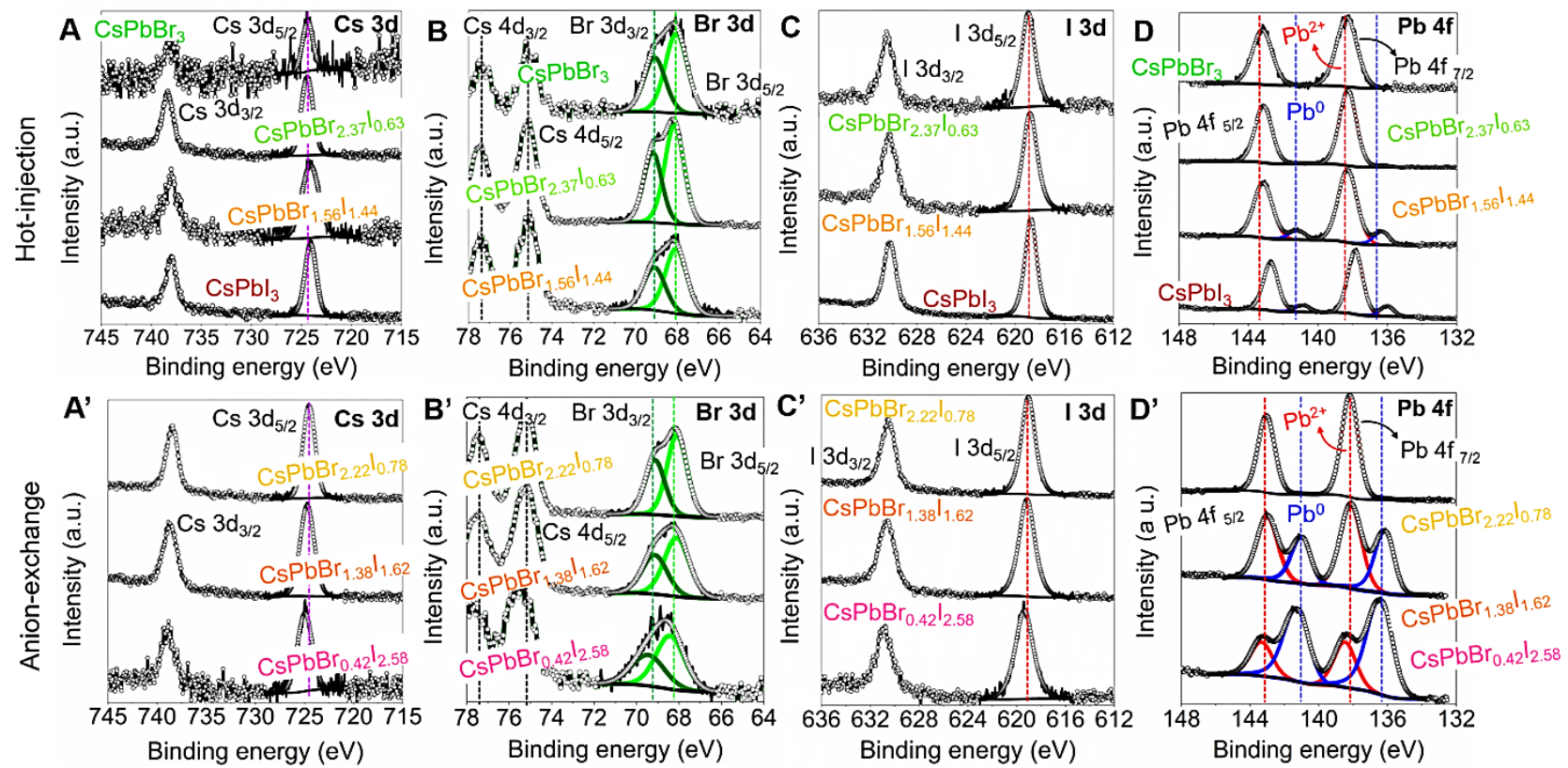

Figure 3. High-resolution XPS spectra of (A, $\left.A^{\prime}\right) \mathrm{Cs} 3 d$, (B, B') $\mathrm{Br} 3 d$, (C,C') I 3d and (D,D') Pb 4f for (A-D) $\mathrm{H}-\mathrm{I}-\mathrm{CsPbBr} \mathrm{Pb}_{3-\mathrm{x}} \mathrm{I}_{\mathrm{x}}$ and (A'-D') A-E-CsPbBr ${ }_{3-\mathrm{x}} \mathrm{I}_{\mathrm{x}}$ nanocrystals.

Table 1. Surface chemical atomic composition of $\mathrm{H}-\mathrm{I}-\mathrm{CsPbBr}{ }_{3-\mathrm{x}} \mathrm{I}_{\mathrm{x}}$ and $\mathrm{A}-\mathrm{E}-\mathrm{CsPbBr}_{3-\mathrm{x}} \mathrm{I}_{\mathrm{x}}$ nanocrystals.

\begin{tabular}{|c|c|c|c|c|c|}
\hline Sample identifier & $\mathrm{Cs}^{+}$(at.\%) & $\mathrm{Pb}^{2+}$ (at.\%) & $\mathrm{Pb}^{0}$ (at.\%) & $\mathrm{Br}^{-}$(at.\%) & $\mathrm{I}^{-}($at. \%) \\
\hline $\mathrm{H}-\mathrm{I}-\mathrm{CsPbBr} \mathrm{Pb}_{3}$ & 6.82 & 33.75 & - & 59.43 & - \\
\hline $\mathrm{H}-\mathrm{I}-\mathrm{CsPbI}{ }_{3}$ & 17.58 & 25.66 & 3.75 & - & 53.01 \\
\hline $\mathrm{H}-\mathrm{I}-\mathrm{CsPbBr} 2.37 \mathrm{I}_{0.63}$ & 12.27 & 25.82 & 0.44 & 53.26 & 8.20 \\
\hline H-I-CsPbBr ${ }_{1.56} \mathrm{I}_{1.44}$ & 10.81 & 28.36 & 4.34 & 29.30 & 27.20 \\
\hline A-E-CsPbBr ${ }_{2.22} \mathrm{I}_{0.78}$ & 18.16 & 21.87 & 0.32 & 36.67 & 22.98 \\
\hline $\mathrm{A}-\mathrm{E}-\mathrm{CsPbBr}{ }_{1.38} \mathrm{I}_{1.62}$ & 16.70 & 18.66 & 13.13 & 31.07 & 20.44 \\
\hline $\mathrm{A}-\mathrm{E}-\mathrm{CsPbBr}{ }_{0.42} \mathrm{I}_{2.58}$ & 9.37 & 13.95 & 35.50 & 20.01 & 21.17 \\
\hline
\end{tabular}

\subsection{Surface photovoltage of hot-injection and anion-exchange mixed halide perovskite nanocrystals}

After establishing the iodide vacancies as the main surface chemical states on H-I and A-E-MHP NCs, it is also clear that PC performances for the oxidation of organic molecules can be significantly affected by these surface states. Therefore, it is essential to clarify their acceptor/donor nature at the MHP lattice. The synthesized NCs were deposited as thin films onto a $\mathrm{TiO}_{2}$ compact layer $\left(\mathrm{C}-\mathrm{TiO}_{2}\right) / \mathrm{FTO}$, in order to observe the surface electrical potential generated by band-to-band (VB maximum $\rightarrow \mathrm{CB}$ minimum) and 
trap-to-band (intraband gap levels $\rightarrow \mathrm{CB}$ minimum) transitions at the NCs surface under illumination. SPV analysis is commonly based on the band bending model of semiconductors as a function of the carrier accumulation at the solid surface. ${ }^{48}$ Upon illumination, acceptor states (n-type semiconductors) or donor states (p-type semiconductors) migrate to the semiconductor surface (depletion layer), where they are balanced with countercharges to produce the space-charge region (SCR). This region has a thickness around $1-10^{3} \mathrm{~nm} .{ }^{49}$ Thereby, a negative SPV is ascribed to the presence of surface acceptor states that accumulate electrons, while a positive SPV corresponds to surface donor states that collect positive charge. ${ }^{50,51}$ For bulk or large particles of a semiconductor $\geq \mathrm{SCR}$, the band bending model can be applied. However, SPV analysis is different for NCs. Here, VB and CB edges do not suffer band bending and the carrier accumulation depends on the carrier diffusion length, which is short for small nanoparticles. ${ }^{49}$

In order to determine the nature of carriers collected at the MHP NCs, surface photovoltage (SPV) measurements were conducted on $\mathrm{H}-\mathrm{I}-\mathrm{CsPbBr} \mathrm{Pb}_{2.37} \mathrm{I}_{0.63}, \mathrm{H}-\mathrm{I}-\mathrm{CsPbBr} \mathrm{Pb}_{1.56} \mathrm{I}_{1.44}$ and $\mathrm{A}-\mathrm{E}-\mathrm{CsPbBr} \mathrm{Pb}_{0.52} \mathrm{I}_{2.58} \mathrm{NCs}$. The contact potential difference (CPD) of these NCs was measured as a function of the illumination intensity. CPD is considered as the potential drop generated between two surfaces in close proximity (in our case, $\mathrm{C}-\mathrm{TiO}_{2} / \mathrm{FTO}$ and perovskites). ${ }^{48}$ By subtracting $\mathrm{CPD}_{\text {light }}-\mathrm{CPD}_{\text {dark }}$, SPV for each material can be obtained. According to Figure S6, the higher the light intensity, the lower the measured CPD. This tendency was ascribed to electron extraction from $\mathrm{MHP}$ to $\mathrm{C}-\mathrm{TiO}_{2} / \mathrm{FTO}$, and hole accumulation at the NC surface. $^{11,50,52}$ Therefore, n-type semiconducting behavior of the MHP could be clearly identified. Nonetheless, the CPD is less negative upon decreasing the Br:I ratio in the NCs. In order to understand this behavior, we studied the SPV vs. light intensity plots obtained for the abovementioned NCs (Figure 4A). Under low light intensity conditions $\left(3 \mathrm{~W} \mathrm{~m}^{-2}\right)$, we evidenced a rapid displacement of SPV to more negative values. Then, SPV was almost constant at higher light intensities. This fact indicates that the maximum capability of charge carrier separation into perovskite NCs can be reached at the lowest light intensity used in these measurements. This ability keeps stable up to the maximum irradiance conditions. Additionally, the negative SPV obtained for the three different NCs involves the presence of surface acceptor states, associated to accumulated surface holes after electron extraction. ${ }^{50,51}$

Comparing the corresponding magnitude of SPV for each nanocrystal, it is also clear that a more positive value was reached upon increasing the iodide content into the $\mathrm{CsPbBr}_{3-\mathrm{x}} \mathrm{I}_{\mathrm{x}}$ lattice. Considering that $\mathrm{H}-\mathrm{I}-\mathrm{CsPbBr}{ }_{2.37} \mathrm{I}_{0.63}$ and $\mathrm{H}-\mathrm{I}-\mathrm{CsPbBr}{ }_{1.56} \mathrm{I}_{1.44}$ were obtained by the same synthesis method, the slight difference in SPV was ascribed to the increase of particle size of MHP. Thus, the carrier diffusion length was increased and the carrier separation slowed down. ${ }^{49}$ Conversely, the markedly increase of SPV magnitude for A-E-CsPbBr ${ }_{0.42} \mathrm{I}_{2.58}$ strongly suggests that the surface chemical states can also influence the surface charge redistribution by trap-to-band transitions. ${ }^{49}$ 
These findings together with the XPS analysis, according to which A-E-MHP produce a higher density of iodide vacancies (and consequently also metallic lead) compared to H-I-MHP, demonstrate that electron extraction from A-E-CsPbBr ${ }_{0.42} \mathrm{I}_{2.58}$ is hindered by these surface states. This fact favors electron trapping. As it has been reported that iodide vacancies are produced by the generation of $\mathrm{Pb}$ dangling bonds, which are located close to the $\mathrm{CB}$ of the perovskite (Figure $4 \mathrm{~B}$ ), ${ }^{53,54}$ we attributed the trap-to-band transitions to electron photoexcitation from $\mathrm{VB}$ to the I vacancy levels and then to the $\mathrm{CB}$ under illumination. Therefore, we conclude that iodide vacancies act as surface donor states for electron trapping at the NCs.

A

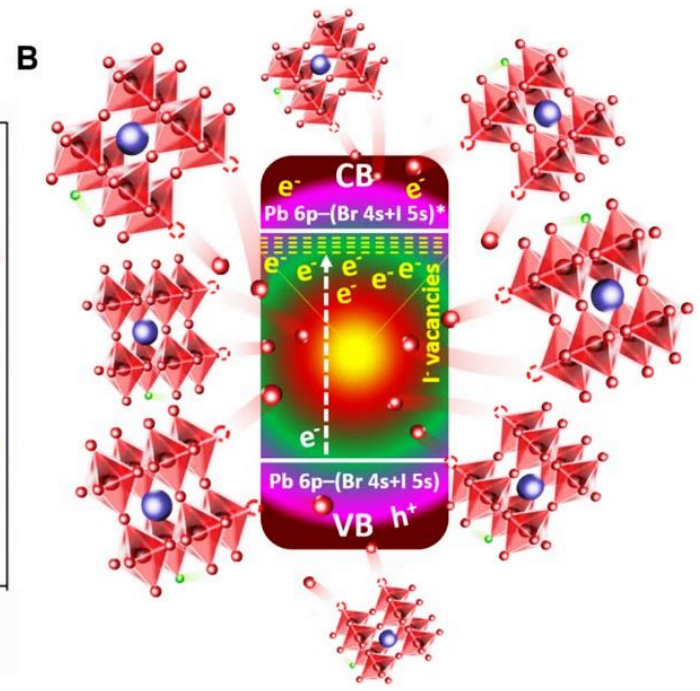

Figure 4. (A) Dependence of SPV with light intensity for $\mathrm{H}-\mathrm{I}-\mathrm{CsPbBr} \mathrm{Pb}_{3-\mathrm{x}} \mathrm{I}_{\mathrm{x}}(\mathrm{x}=0.63,1.44)$ and A-E$\mathrm{CsPbBr}_{3-\mathrm{x}} \mathrm{I}_{\mathrm{x}}(\mathrm{x}=2.58)$ nanocrystal films. (B) Schematic illustration of iodide vacancies into the band structure of a $\mathrm{CsPBr}_{3-\mathrm{x}} \mathrm{I}_{\mathrm{x}}$ perovskite.

\subsection{Band structure of the hot-injection and anion-exchange mixed halide perovskites}

The band gap of NCs plays a key role on the PC activity as a narrower band gap produce higher photon harvesting but the energetic band position also influences the PC activity as more positive energy position of the VB ( $v s$. Fermi level), increases the oxidizing power of the MHP photocatalysts. Consequently, the final PC activity is strongly determined by both band gap and energy position. Therefore, to understand the correlation between electronic structure and PC activity for H-I-MHP and AE-MHP NCs, their corresponding $\mathrm{VB}$ and $\mathrm{CB}$ relative positions were determined. By obtaining normalized XPS VB spectra (Figures S7A,B), the valence band energy $\left(\mathrm{E}_{\mathrm{VB}}\right)$ was determined for all the perovskites through the extrapolation method. Then, the equation $E_{V B}=E_{C B}+E_{g}$ was used to calculate 
the associated conduction band energy $\left(\mathrm{E}_{\mathrm{CB}}\right)$ and thereby estimate the band structure. The obtained energy levels are in good agreement with band structures extracted from electrochemical measurements for these perovskites NCs. ${ }^{11}$ As seen in Figure 5A, on one hand, the $\mathrm{E}_{\mathrm{VB}}$ of H-I-MHP is shifted to more negative values ( $v s$. Fermi level) by increasing the iodide content, consequently decreasing the oxidizing power of the MHP photocatalysts. On the other hand, higher iodide content narrows the band gap, increasing the light harvesting. In this sense, the bandgap and the energy band position of H-I-MHP NCs follow different trends, with the increase of iodide contend, respect favoring the PC activity.

Conversely, a different behavior was observed for A-E-MHP NCs. By decreasing the Br:I ratio (Figure 5B), the band gap was narrowed too, but $\mathrm{E}_{\mathrm{VB}}$ was shifted to more positive values, increasing the oxidizing power of VB holes. Thus, the surface chemical states discussed above suggests that the higher density of iodide vacancies found in A-E-MHP does not only provide donor energy levels below the bottom-edge of $\mathrm{CB}$ but also influences the band position. These iodide-deficient domains also facilitate the exposure of Br-domains from A-E-MHP. Therefore, $\mathrm{Br} 2 \mathrm{p}$ orbitals govern the VB position. According with the band structure obtained for each perovskite NC, we propose that both H-I-MHP and A-E-MHP can provide a high PC activity for performing the $\beta$-naphthol ( $\beta$-NPT) photodegradation but the different band position will influence which NC composition will produce the better PC activity depending on the synthesis process. In addition, the different density of surface chemical states of these materials suggests that diverse organic oxidation pathways could be followed, as we analyzed in the next section. 

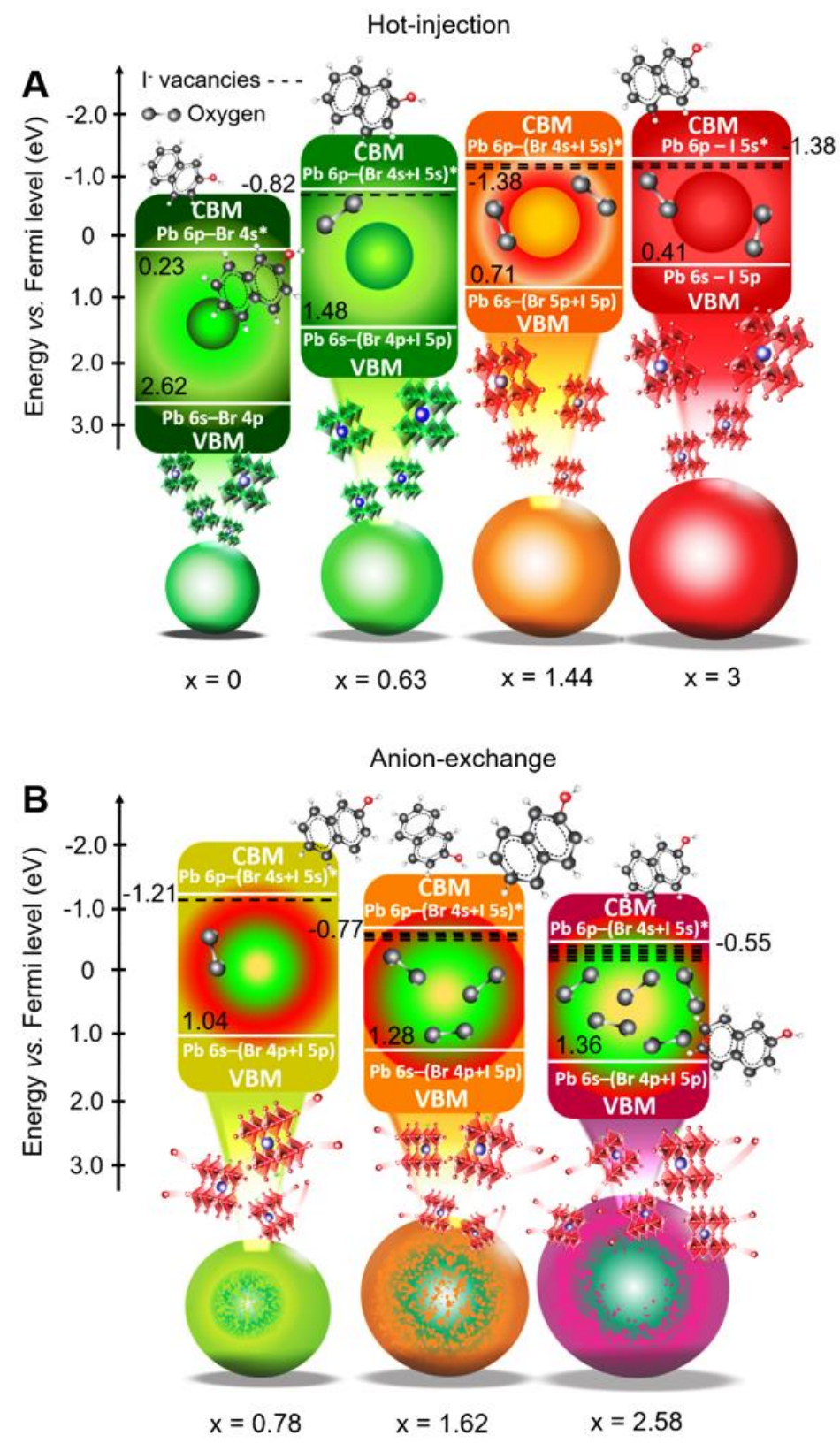

Figure 5. Band structure of (A) H-I-CsPbBr $3-\mathrm{x} \mathrm{I}_{\mathrm{x}}$ and (B) A-E-CsPbBr ${ }_{3-\mathrm{x}} \mathrm{I}_{\mathrm{x}}$ nanocrystals, obtained from XPS VB spectra through the extrapolation method.

\subsection{Photocatalytic activity of mixed halide perovskite nanocrystals for $\beta$-naphthol degradation}

After analyzing the role of iodide-deficient domains on the photophysical, surface properties and band structure of MHP NCs, we carried out the photo-oxidation of an organic compound under air atmosphere, with both H-I and A-E-MHP, using $\beta$-naphthol ( $\beta$-NPT) as a generic compound. We followed the typical UV-Vis absorbance band from the organic compound during 90 min reaction time, in 
the absence and presence of MHP photocatalysts under continuous visible light irradiation (Figures S8A$\mathrm{H})$. Changes in the absorbance of $\beta$-NPT $\left(\mathrm{C} / \mathrm{C}_{\mathrm{o}}\right)$ were tracked at $15 \mathrm{~min}$ intervals (Figure $6 \mathrm{~A}$ ), where $\mathrm{C}$ is the concentration and $\mathrm{C}_{\mathrm{o}}$ the initial concentration. From the degradation curves, a pseudo-first-order rate constant $(k)$ was determined for each photocatalyst (Figure 6A'). This parameter was determined from $\operatorname{Ln}\left(\mathrm{C}_{\mathrm{o}} / \mathrm{C}\right)=k \mathrm{t}$, being $\mathrm{t}$ the reaction time. The corresponding $k$ values obtained for each perovskite are summarized in Table S3. First, the photolytic process (absence of MHP photocatalysts) did not provide any meaningful change on the $\mathrm{C} / \mathrm{C}_{\mathrm{o}}$ relative concentration of the organic compound, confirming its recalcitrant behavior under visible light. Then, PC performances of the H-I-MHP NCs were compared as a function of their corresponding band gap, where the maximum photodegradation efficiency was around $61 \%$, for $\mathrm{H}-\mathrm{ICsPbBr}_{2.37} \mathrm{I}_{0.63} \mathrm{NCs}$ (Figure S9A). This material also exhibited the highest $k$, associated to the fastest degradation process occurring at the NC surface. ${ }^{11}$ Higher iodide content led to the deactivation of the PC activity. Conversely, the highest PC performances of the A-E-MHP NCs around $37 \%$ and $57 \%$ were achieved for A-E-CsPbBr ${ }_{2.22} \mathrm{I}_{0.78}$ and A-E-CsPbBr ${ }_{0.42} \mathrm{I}_{2.58}$, respectively (Figure $\mathrm{S} 9 \mathrm{~B}$ ). The highest PC performance is obtained for NCs with different bandgap depending of the synthesis process due to the different energy position, as discussed in section 2.3., but also different chemical reaction could take place owing to the different surface nature, as we analyzed below.

As previously demonstrated by XPS and SPV analyses, A-E-MHP NCs displayed a high density of iodide vacancies, which made them more prone to incorporate $\mathrm{O}_{2}$ molecules. However, it has been reported that the introduced $\mathrm{O}_{2}$ species can generate superoxide ions, $\mathrm{O}_{2}{ }^{\bullet-}$, by trapping the photoexcited electrons from the perovskite. ${ }^{25,26,39,46,55}$ For solar cells application, the presence of $\mathrm{O}_{2}$ slows down the electron transport through the devices, decreasing the photoconversion efficiency. ${ }^{39,55}$ For photocatalysis, $\mathrm{O}_{2}$ can act as an electron scavenger to produce $\mathrm{O}_{2}{ }^{\bullet-}$ species, preventing carrier recombination. ${ }^{39,49}$ This fact increases the density of available photoexcited holes at the photocatalyst, which significantly enhances its PC activity. In this context, the observed PC performances for A-E-CsPbBr ${ }_{3-\mathrm{x}} \mathrm{I}_{\mathrm{x}}$ can be explained in terms of the ease for $\mathrm{O}_{2}$ incorporation at the $\mathrm{NC}$ surface. A-E-CsPbBr ${ }_{2.22} \mathrm{I}_{0.78} \mathrm{NCs}$ shows the lowest density of iodide vacancies, which is high enough to allow the introduction of a slight $\mathrm{O}_{2}$ fraction into its structure. This fact was evidenced by observing a blue shift in the PL peak of the A-E$\mathrm{CsPbBr}_{2.22} \mathrm{I}_{0.78}$ after 90 days under air, indicating the self-degradation of the perovskite (Figure S4B,B'). ${ }^{40}$ However, the remained green luminescence of $\mathrm{A}-\mathrm{E}-\mathrm{Cs} \mathrm{PbBr}_{2.22} \mathrm{I}_{0.78}$ also suggest that the incorporated $\mathrm{O}_{2}$ is not enough to promote the complete degradation of the MHP.

Conversely, a higher density of iodide vacancies evidenced at the A-E-CsPbBr ${ }_{0.42} \mathrm{I}_{2.58} \mathrm{NCs}$ can facilitate the diffusion of a higher fraction of $\mathrm{O}_{2}$ to generate more $\mathrm{O}_{2}{ }^{\bullet-}$ species. However, we also concluded that the iodide-rich MHP can be more easily fast-self-degraded. Thus, the PC activity of A-E- 
MHP does not only depend on the presence of accumulated photoexcited holes, but also on the density of highly reactive $\mathrm{O}_{2}{ }^{\bullet-}$ species produced at the NCs. Therefore, the $\beta$-NPT degradation pathway by using AE-CsPbBr ${ }_{0.42} \mathrm{I}_{2.58} \mathrm{NC}$ is mediated by these $\mathrm{O}_{2}{ }^{\bullet-}$ species at the $\mathrm{NC} /$ solution interface. At this stage, it is clear that a balance between the instability and the PC activity of the A-H-MHP can be concluded: iodide vacancy-rich A-E-MHP shows a high PC performance as the result of a high density of $\mathrm{O}_{2}^{\bullet-}$ species. Nonetheless, short times would be required to use these materials in PC oxidation reactions before to evidence their fast-self-degradation. Conversely, the PC activity of A-E-MHP with lower density of iodide vacancies (slow-self-degradation) could be studied at longer times, which could compensate their low formation of $\mathrm{O}_{2}{ }^{--}$species to photodegrade organic compounds. Nonetheless, On the other hand, the PC activity of H-I-MHP NCs is based on an appropriate balance between the band gap and highly oxidizing VB relative position. This fact clearly suggests that with $\mathrm{H}-\mathrm{I}-\mathrm{CsPbBr} \mathrm{Pb}_{2.37} \mathrm{I}_{0.63} \mathrm{NCs}$, the $\beta-\mathrm{NPT}$ degradation pathway follows the direct reaction with photoexcited holes.

In order to further confirm the $\beta$-NPT degradation pathways followed by using either H-I-MHP or AE-MHP, ATR-IR spectra were acquired on the systems with the highest PC performance. The decrease of main peaks from the organic molecule was evidenced as the reaction time increases (Figure 6B,C,B', C') indicating the degradation of $\beta$-NPT. Two peaks at 3188.2 and $3394.3 \mathrm{~cm}^{-1}$ were ascribed to $=\mathrm{C}-\mathrm{H}$ and O-H asymmetrical stretching, respectively (Figures 6B,B'), while the signals at 1645.8 and $1730.0 \mathrm{~cm}^{-1}$ corresponded to $\mathrm{C}=\mathrm{C}$ aromatic bond stretching from the naphthalene rings (Figures 6C, $\mathrm{C}^{\prime}$ ). ${ }^{56}$ The presence of $\mathrm{H}-\mathrm{I}-\mathrm{Cs} \mathrm{PbBr}_{2.37} \mathrm{I}_{0.63} \mathrm{NCs}$ eventually quenches the absorbance of these peaks at 1645.8 and $1730.0 \mathrm{~cm}^{-1}$ (Figures 6B,C). After $90 \mathrm{~min}$ reaction time, a different type of $\mathrm{O}-\mathrm{H}$ stretch vibration appeared in the spectra. We consider that the low density of iodide vacancies found in $\mathrm{H}-\mathrm{I}-\mathrm{CsPbBr}{ }_{2.37} \mathrm{I}_{0.63} \mathrm{NCs}$ allows the production of a small density of $\mathrm{O}_{2}{ }^{\bullet-}$ species contributing to the organic degradation process. However, the progressive reduction of ATR-IR vibration modes of $\beta$-NPT is a clear evidence of the direct reaction between photoexcited holes generated at the photocatalyst and the organic compound. We concluded that this behavior is the key factor for the PC activity of H-I-MHP. Regarding A-E$\mathrm{CsPbBr}_{0.42} \mathrm{I}_{2.58} \mathrm{NCs}$, the absorption bands describing the vibrational modes of the $\beta$-NPT were rapidly diminished after 30 min reaction time (Figures 6B',C'). Surprisingly, the decay of these signals turned slower (as a result of a decreased PC activity), as the $\mathrm{O}-\mathrm{H}$ vibration peak progressively became more intense and broader. 

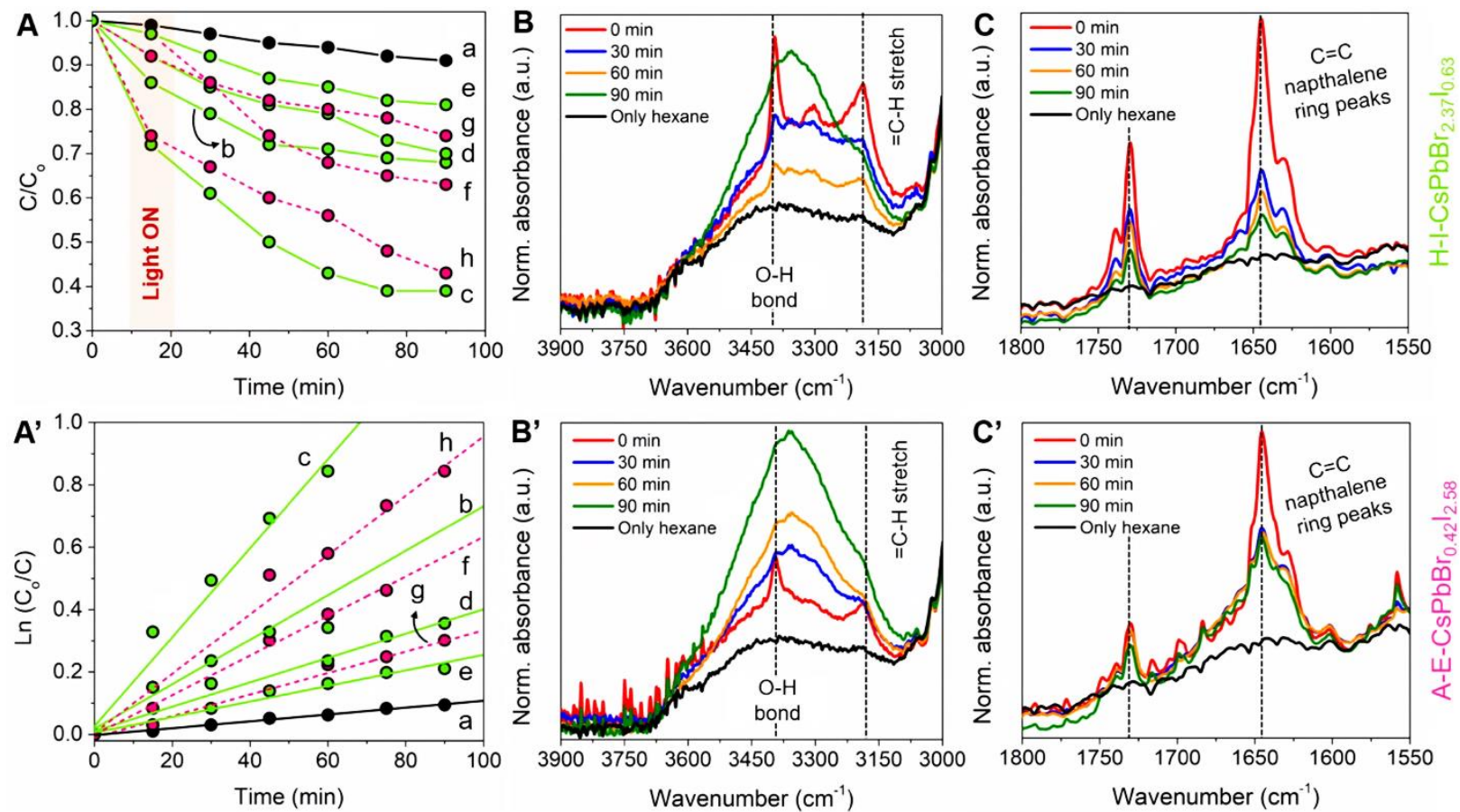

Figure 6. (A) Photodegradation of $\beta$-naphthol $(0.2 \mathrm{mM})$ vs. time and (A') corresponding kinetic rate curves obtained (a) in absence and presence of $\mathrm{H}-\mathrm{I}-\mathrm{CsPbBr}{ }_{3-\mathrm{x}} \mathrm{I}_{\mathrm{x}}$ (solid line, green) $[(\mathrm{b}) \mathrm{x}=0,(\mathrm{c}) \mathrm{x}=0.63$, (d) $\mathrm{x}=1.44$, (e) $\mathrm{x}=3$ )], and A-E-CsPbBr ${ }_{3-\mathrm{x}} \mathrm{I}_{\mathrm{x}}$ (dashed line, pink) [(f) $\mathrm{x}=0.78,(\mathrm{~g}) \mathrm{x}=1.62$ and (h) $\mathrm{x}=$ 2.58] perovskite nanocrystals under $\mathrm{O}_{2}$ atmosphere. Progressive decrease of IR vibration modes of (B,B') hydroxyl group and $\left(\mathrm{C}, \mathrm{C}^{\prime}\right)$ naphthalene ring during the photocatalytic $\beta$-naphthol oxidation by using $(\mathrm{B}, \mathrm{C})$ $\mathrm{H}-\mathrm{I}-\mathrm{CsPbBr}{ }_{2.37} \mathrm{I}_{0.63}$ and (B'C') A-E-CsPbBr ${ }_{0.42} \mathrm{I}_{2.58}$ perovskites $\left(2.5 \mathrm{mg} \mathrm{mL}^{-1}\right)$. Illumination source: halide $\operatorname{lamp}\left(60 \mathrm{~mW} \mathrm{~cm}^{-2}\right)$.

Considering that A-E-MHP contains a high density of iodide vacancies into its structure, we consider that there is a proportional fraction of $\mathrm{O}_{2}$ diffused to the photocatalyst for producing a high density of $\mathrm{O}_{2}{ }^{\bullet-}$ species under illumination. Nevertheless, the formed $\mathrm{O}_{2}{ }^{\bullet-}$ can react with the aromatic compound through proton/electron transfer pathway, described as follows (reactions 1-5): ${ }^{30}$

$$
\begin{gathered}
\mathrm{O}_{2}+\mathrm{e}^{-} \rightleftarrows \mathrm{O}_{2}^{--} \\
\mathrm{O}_{2}^{\circ-}+\mathrm{C}_{10} \mathrm{H}_{7} \mathrm{OH} \\
\mathrm{HO}_{2}^{\circ}+\mathrm{O}_{2}^{\circ-} \rightarrow \mathrm{HO}_{2}^{-}+\mathrm{C}_{10} \mathrm{H}_{7} \mathrm{O}^{-} \\
\mathrm{HO}_{2}^{\circ}+\mathrm{O}^{-} \rightarrow \mathrm{HO}_{2}^{-} \\
\mathrm{HO}_{2}^{-}+\mathrm{C}_{10} \mathrm{H}_{7} \mathrm{OH} \rightarrow \mathrm{H}_{2} \mathrm{O}_{2}+\mathrm{C}_{10} \mathrm{H}_{7} \mathrm{O}^{-}
\end{gathered}
$$


The generated $\mathrm{O}_{2}{ }^{\bullet-}$ species (weak base) cause the deprotonation of $\beta$-NPT (Brönsted acid), to produce hydroperoxide radicals $\left(\mathrm{HO}_{2}{ }^{\bullet}\right)$ and naphtholate anions, respectively. $\mathrm{HO}_{2}^{\bullet}$ are rapidly converted to hydroperoxide anions $\left(\mathrm{HO}_{2}^{-}\right)$by reacting with other $\mathrm{O}_{2}{ }^{--}$species or photogenerated electrons at the MHP. Then, $\mathrm{HO}_{2}{ }^{-}$also induces the $\mathrm{H}^{+}$-transfer from the organic compound to obtain hydrogen peroxide $\left(\mathrm{H}_{2} \mathrm{O}_{2}\right)$ as a secondary reaction product in the solution. This reaction mechanism has been reported as a concerted double proton-transfer electron transfer reaction (CDPET) ${ }^{57}$ Correlating the CDEPT process with the PC activity of A-E-CsPbBr ${ }_{0.42} \mathrm{I}_{2.58}$, we can hypothesize that the fast increase in the density of $\mathrm{O}_{2}{ }^{\bullet-}$ species produced under illumination can also generate enough highly reactive $\mathrm{HO}_{2}{ }^{-}$species for carrying out the organic deprotonation and $\mathrm{H}_{2} \mathrm{O}_{2}$ release. We contemplate that this is the reason for the eventual increase of the absorbance corresponding to the $\mathrm{O}-\mathrm{H}$ vibration mode and the stopped-decrease of $\mathrm{C}=\mathrm{C}$ naphthalene bands. This fact indicates that CDEPT is the first step in the $\beta$-NPT degradation pathway using A-E-MHP. In order to experimentally validate that A-E-CsPbBr ${ }_{0.42} \mathrm{I}_{2.58}$ follows a CDEPT-type mechanism, we probed the presence of $\mathrm{H}_{2} \mathrm{O}_{2}$ after organic photodegradation, by reaction with potassium iodide (KI). Here, changes in the PL features from the reaction mixture containing an A-E-MHP NC sample and $\beta$-NPT were observed after KI addition (Figure S10, supporting video 1 and 2) (See supporting information for more details). However, although the complete $\beta$-NPT photodegradation was not observed in the ATR-IR spectra after using A-E-MHP, we infer that the $\mathrm{O}_{2}{ }^{--}$species can also directly degrade the organic molecules to obtain non-radical products (reactions 6 and 7). ${ }^{29,}{ }^{30}$ Hence, the decrease of $C / C_{o}$ relative concentration of $\beta$-NPT can be reached:

$$
\begin{aligned}
& \mathrm{O}_{2}^{\bullet-}+\mathrm{C}_{10} \mathrm{H}_{7} \mathrm{OH} \rightarrow \mathrm{HO}_{2}^{-}+\mathrm{C}_{10} \mathrm{H}_{7} \mathrm{O}^{\bullet} \\
& \mathrm{C}_{10} \mathrm{H}_{7} \mathrm{O}^{\bullet} \rightarrow \text { non radical products }
\end{aligned}
$$

Previous reports have reported that phenoxy-based radicals from the reaction of phenolic compounds and $\mathrm{O}_{2}{ }^{--}$are prone to form dimers, oligomers, or/and quinones as the main non-radical products in organic media. $^{29,30}$

Another useful strategy to analyze the effect of $\mathrm{O}_{2}$ on the PC performance of MHP was by conducting the photodegradation measurements under inert atmosphere. Figures S11A,B show the UV-Vis absorption spectra of $\beta$-NPT by using H-I-CsPbBr $2.37 \mathrm{I}_{0.63}$ and A-E-CsPbBr ${ }_{0.42} \mathrm{I}_{2.58}$ NCs as photocatalysts under $\mathrm{N}_{2}$-purge. Here, $\mathrm{C} / \mathrm{C}_{\mathrm{o}}$ vs. reaction time plots were extracted (Figure $\mathrm{S} 11 \mathrm{C}$ ). After $90 \mathrm{~min}$, the organic molecule was photodegraded on $31 \%$ and $22 \%$, respectively, indicating a decrease of PC activity for both H-I-MHP and A-E-MHP compared to their performances under $\mathrm{O}_{2}$ atmosphere. Simultaneously, ATR-IR also displayed the highest/lowest photo-oxidation ability of H-I-MHP/A-E-MHP photocatalysts to degrade $\beta$-NPT, without the appearance of the broad $\mathrm{O}-\mathrm{H}$ vibration peak associated to the production 
of $\mathrm{H}_{2} \mathrm{O}_{2}$ (Figure S12). Although it is clear that the PC performance of MHP is enhanced by the presence of $\mathrm{O}_{2}$, it is still evident that the quenching of the IR vibration modes of $\beta$-NPT by using H-I$\mathrm{CsPbBr}_{2.37} \mathrm{I}_{0.63}$ NCs. This behavior suggests that the organic degradation pathway is conducted by direct reaction with photoexcited holes. Meanwhile, A-E-CsPbBr ${ }_{0.42} \mathrm{I}_{2.58} \mathrm{NCs}$ exhibited a "non- $\mathrm{O}_{2}$-shielded" lower PC performance. This fact indicated that formation of $\mathrm{O}_{2}{ }^{--}$species was inhibited, leading to charge carrier recombination into the perovskite NCs. Accordingly, we claim that the presence of $\mathrm{O}_{2}{ }^{--}$species is the dominant factor dictating the PC activity of A-E-MHP. On the contrary, the low density of these ions in H-I-MHP indicates that their PC performance is attributed to the appropriate band gap and band relative positions to produce a high density of highly-oxidizing photoexcited holes.

\section{Conclusions}

In this work, we have synthesized MHP by H-I and A-E methods, where their band gap and relative band positions have been tuned by varying the halide content. After determining the photophysical and surface properties of H-I-MHP and A-E-MHP, we identified iodide vacancies as the main surface chemical states that govern the PC activity of MHP NCs for the degradation of organic molecules, causing also a different alignment of energetic bands. In the case of A-E-MHP, a high density of these species was produced due to the different ability of iodide and bromide anions to migrate during the halide exchange process. This fact generates inhomogeneous iodide domains at the NC surface. On the other hand, by stoichiometrically mixing the precursors to synthesize H-I-MHP, both the iodide and bromide domains are established into the perovskite lattice. Therefore, the halide gradient responsible for the generation of iodide vacancies was decreased. A-E-MHP was more prone to facilitate the oxygen incorporation, generating a higher density of reactive $\mathrm{O}_{2}{ }^{\bullet-}$ species compared to H-I-MHP. The presence of $\mathrm{O}_{2}{ }^{\bullet-}$ species dictates the PC activity of A-E-MHP for carrying out the $\beta$-NPT photodegradation through a CDEPT mechanism. Conversely, the low fraction of iodide vacancies at H-I-MHP suggests that their PC activity is controlled by an appropriate balance between the band gap energy and relative band positions. Thereby, a high density of photoexcited holes can be generated at the perovskite NCs to oxidize $\beta$-NPT at the photocatalyst/solution interface. This study provides a novel perspective about the structure-reactivity relationship on MHP NCs, with important implications in the future design of novel photocatalyst. 


\section{ASSOCIATED CONTENT}

Supporting Information. Experimental section, XRD patterns, emission spectra, FWHM from emission curves, XPS survey spectra, topography and contact potential difference (CPD) under dark and at different light intensities percentages, and XPS valance band spectra for $\mathrm{H}-\mathrm{I}-\mathrm{CsPbBr} \mathrm{P}_{3-\mathrm{x}} \mathrm{I}_{\mathrm{x}}$ and A-E-CsPbBr ${ }_{3-\mathrm{x}} \mathrm{I}_{\mathrm{x}}$ nanocrystals, tracking of $\beta$-naphthol photodegradation by $\mathrm{UV}-\mathrm{Vis}$ spectroscopy under $\mathrm{O}_{2}$ and $\mathrm{N}_{2}$ atmospheres and photos of photoluminescent nanocrystals.

\section{AUTHOR INFORMATION}

\section{Corresponding Author}

*Address correspondence to this author: sero@uji.es, Twitter: @IvanMoraSero, gualdron@uji.es, Twitter: @GualdronReyes

\section{AUTHOR CONTRIBUTIONS}

J.R.-P. and A.F.G.-R. conceived the idea. A.F.G.-R., S.G. and I.M.-S. designed the experiments. A.F.G.R and S. J. Y. synthesized the perovskite nanocrystals. S. A. and V. M.-S. conducted the TEM and EDS measurements of the materials. A.F.G.-R., E.A.-G. and J.E.R.-P. performed the photophysical characterization. S.M. conducted the XRD. J.R.-P. and R.O. contributed to the XPS and ATR-IR measurements. J.T. and F.J. performed the SPV measurements. S.G. and I.M.-S. provided advice and expertise. A.F.G.-R. carried out the PC organic degradation. A.F.G.-R wrote the original draft of the manuscript, and all authors contributed to the final version of the manuscript.

\section{DECLARATION OF INTERESTS}

The authors declare no competing interests

\section{ACKNOWLEDGMENT}

This work was supported by Universidad de Pamplona, Internal project 2019 and project GA313-BP-2017. A. F. Gualdrón-Reyes acknowledges to COLCIENCIAS for the Ph.D. 617-scholarship. 
We thank Santiago Mesa from Laboratorio de Celdas Solares-CIDEMAT for his assistance for SPV measurements. We thank to Laboratorio de Rayos X and Laboratorio de Ciencia de Superficies (SurfLabUIS) from Universidad Industrial de Santander for the XRD measurements and providing their facilities to perform the XPS measurements, respectively. This work was also partially supported by European Research Council (ERC) via Consolidator Grant (724424-No-LIMIT), EU (FEDER) under project TEC2017-85912-C2-2, the Spanish Ministerio de Ciencia, Innovación y Universidades through the project ENE2017-85087-C3-1-R and Generalitat Valenciana via Prometeo Grant Q-Devices (Prometeo/2018/098). We acknowledge the SCSIE from the University of Valencia for providing TEM facilities. 


\section{References}

(1) Akkerman, Q. A.; Rainò, G.; Kovalenko, M. V.; Manna, L. Genesis, Challenges and Opportunities for Colloidal Lead Halide Perovskite Nanocrystals. Nat. Mater. 2018, 17 (5), 394-405.

(2) Creutz, S. E.; Crites, E. N.; De Siena, M. C.; Gamelin, D. R. Anion Exchange in Cesium Lead Halide Perovskite Nanocrystals and Thin Films Using Trimethylsilyl Halide Reagents. Chem. Mater. 2018, 30 (15), 4887-4891.

(3) Zhao, Q.; Hazarika, A.; Chen, X.; Harvey, S. P.; Larson, B. W.; Teeter, G. R.; Liu, J.; Song, T.; Xiao, C.; Shaw, L.; Zhang, M.; Li, G.; Beard, M. C.; Luther, J. M. High Efficiency Perovskite Quantum Dot Solar Cells with Charge Separating Heterostructure. Nature Communications 2019, 10 (1) 2842.

(4) Protesescu, L.; Yakunin, S.; Bodnarchuk, M. I.; Krieg, F.; Caputo, R.; Hendon, C. H.; Yang, R. X.; Walsh, A.; Kovalenko, M. V. Nanocrystals of Cesium Lead Halide Perovskites $\left(\mathrm{CsPbX}_{3}, \mathrm{X}=\mathrm{Cl}\right.$, $\mathrm{Br}$, and I): Novel Optoelectronic Materials Showing Bright Emission with Wide Color Gamut. Nano Lett. 2015, 15 (6), 3692-3696.

(5) Haque, A.; Ravi, V. K.; Shanker, G. S.; Sarkar, I.; Nag, A.; Santra, P. K. Internal Heterostructure of Anion-Exchanged Cesium Lead Halide Nanocubes. J. Phys. Chem. C 2017, 122 (25), 1339913406.

(6) Xu, Y.-F.; Yang, M.-Z;; Chen, B.-X.; Wang, X.-D.; Chen, H.-Y.; Kuang, D.-B.; Su, C.-Y. A $\mathrm{CsPbBr}_{3}$ Perovskite Quantum Dot/Graphene Oxide Composite for Photocatalytic $\mathrm{CO}_{2}$ Reduction. $J$. Am. Chem. Soc. 2017, 139 (16), 5660-5663.

(7) Huang, H.; Yuan, H.; Janssen, K. P. F.; Solís-Fernández, G.; Wang, Y.; Tan, C. Y. X.; Jonckheere, D.; Debroye, E.; Long, J.; Hendrix, J.; Hofkens, J.; Steele, J. A.; Roeffaers, M. B. J. Efficient and Selective Photocatalytic Oxidation of Benzylic Alcohols with Hybrid OrganicInorganic Perovskite Materials. ACS Energy Lett. 2018, 3 (4), 755-759.

(8) Gao, G.; Xi, Q.; Zhou, H.; Zhao, Y.; Wu, C.; Wang, L.; Guo, P.; Xu, J. Novel Inorganic Perovskite Quantum Dots for Photocatalysis. Nanoscale 2017, 9 (33), 12032-12038.

(9) Gualdrón-Reyes, A. F.; Yoon, S. J.; Barea, E. M.; Agouram, S.; Muñoz-Sanjosé, V.; Meléndez, Á. M.; Niño-Gómez, M. E.; Mora-Seró, I. Controlling the Phase Segregation in Mixed Halide Perovskites through Nanocrystal Size. ACS Energy Lett. 2018, 4 (1), 54-62.

(10) Liu, H.; Tan, Y.; Cao, M.; Hu, H.; Wu, L.; Yu, X.; Wang, L.; Sun, B.; Zhang, Q. Fabricating $\mathrm{CsPbX}_{3}$-Based Type I and Type II Heterostructures by Tuning the Halide Composition of Janus $\mathrm{CsPbX} / \mathrm{ZrO}_{2}$ Nanocrystals. ACS Nano 2019, 13 (5), 5366-5374.

(11) Cardenas-Morcoso, D.; Gualdrón-Reyes, A. F.; Ferreira Vitoreti, A. B.; García-Tecedor, M.; Yoon, S. J.; Solis de la Fuente, M.; Mora-Seró, I.; Gimenez, S. Photocatalytic and Photoelectrochemical Degradation of Organic Compounds with All-Inorganic Metal Halide Perovskite Quantum Dots. J. Phys. Chem. Lett. 2019, 10 (3), 630-636.

(12) Cui, W.; Chen, L.; Li, J.; Zhou, Y.; Sun, Y.; Jiang, G.; Lee, S. C.; Dong, F. Ba-Vacancy Induces Semiconductor-Like Photocatalysis on Insulator $\mathrm{BaSO}_{4}$. Appl. Catal. B: Environ. 2019, 253, 293-299.

(13) Yang, T. C.-J.; Fiala, P.; Jeangros, Q.; Ballif, C. High-Bandgap Perovskite Materials for Multijunction Solar Cells. Joule 2018, 2 (8), 1421-1436.

(14) Braly, I. L.; Stoddard, R. J.; Rajagopal, A.; Uhl, A. R.; Katahara, J. K.; Jen, A. K. Y.; Hillhouse, H. W. Current-Induced Phase Segregation in Mixed Halide Hybrid Perovskites and its Impact on Two-Terminal Tandem Solar Cell Design. ACS Energy Letter. 2017, 2 (8), 1841-1847.

(15) Gil-Escrig, L.; Miquel-Sempere, A.; Sessolo, M.; Bolink, H. J. Mixed Iodide-Bromide Methylammonium Lead Perovskite-based Diodes for Light Emission and Photovoltaics. J. Phys. Chem. Lett. 2015, 6 (18), 3743-3748. 
(16) Chen, K.; Deng, X.; Dodekatos, G.; Tüysüz, H. Photocatalytic Polymerization of 3,4Ethylenedioxythiophene over Cesium Lead Iodide Perovskite Quantum Dots. J. Am. Chem. Soc. 2017, 139 (35), 12267-12273.

(17) Hou, J.; Cao, S.; Wu, Y.; Gao, Z.; Liang, F.; Sun, Y.; Lin, Z.; Sun, L. Inorganic Colloidal Perovskite Quantum Dots for Robust Solar $\mathrm{CO}_{2}$ Reduction. Chem. Eur. J. 2017, 23 (40), 9481-9485.

(18) Guan, Z.; Wu, Y.; Wang, P.; Zhang, Q.; Wang, Z.; Zheng, Z.; Liu, Y.; Dai, Y.; Whangbo, M.-H.; Huang, B. Perovskite Photocatalyst $\mathrm{CsPbBr}_{3-\mathrm{x}} \mathrm{I}_{\mathrm{x}}$ with a Bandgap Funnel Structure for H2 Evolution Under Visible Light. Appl. Catal. B: Environ. 2019, 245, 522-527.

(19) Wu, Y.; Wang, P.; Guan, Z.; Liu, J.; Wang, Z.; Zheng, Z.; Jin, S.; Dai, Y.; Whangbo, M.-H.; Huang, B. Enhancing the Photocatalytic Hydrogen Evolution Activity of Mixed-Halide Perovskite $\mathrm{CH}_{3} \mathrm{NH}_{3} \mathrm{PbBr}_{3-\mathrm{x}} \mathrm{I}_{\mathrm{x}}$ Achieved by Bandgap Funneling of Charge Carriers. ACS Catal. 2018, 8 (11), 10349-10357.

(20) Akkerman, Q. A.; D’Innocenzo, V.; Accornero, S.; Scarpellini, A.; Petrozza, A.; Prato, M.; Manna, L. Tuning the Optical Properties of Cesium Lead Halide Perovskite Nanocrystals by Anion Exchange Reactions. J. Am. Chem. Soc. 2015, 137 (32), 10276-10281.

(21) Li, X.; Wu, Y.; Zhang, S.; Cai, B.; Gu, Y.; Song, J.; Zeng, H. CsPbX 3 Quantum Dots for Lighting and Displays: Room-Temperature Synthesis, Photoluminescence Superiorities, Underlying Origins and White Light-Emitting Diodes. Adv. Funct. Mater. 2016, 26 (15), 2435-2445.

(22) Nedelcu, G.; Protesescu, L.; Yakunin, S.; Bodnarchuk, M. I.; Grotevent, M. J.; Kovalenko, M. V. Fast Anion-Exchange in Highly Luminescent Nanocrystals of Cesium Lead Halide Perovskites $\left(\mathrm{CsPbX}_{3}, \mathrm{X}=\mathrm{Cl}, \mathrm{Br}, \mathrm{I}\right)$. Nano Letter. 2015, 15 (8), 5635-5640.

(23) Karimata, I.; Kobori, Y.; Tachikawa, T. Direct Observation of Charge Collection at NanometerScale Iodide-Rich Perovskites during Halide Exchange Reaction on $\mathrm{CH}_{3} \mathrm{NH}_{3} \mathrm{PbBr}_{3}$. J. Phys. Chem. Lett. 2017, 8 (8), 1724-1728.

(24) Senocrate, A.; Acartürk, T.; Kim, G. Y.; Merkle, R.; Starke, U.; Grätzel, M.; Maier, J. Interaction of Oxygen with Halide Perovskites. J. Mater. Chem. A 2018, 6 (23), 10847-10855.

(25) Rocks, C.; Svrcek, V.; Maguire, P.; Mariotti, D. Understanding Surface Chemistry During $\mathrm{MAPbI}_{3}$ Spray Deposition and its Effect on Photovoltaic Performance. J. Mater. Chem. C 2017, 5 (4), 902-916.

(26) Anaya, M.; Galisteo-López, J. F.; Calvo, M. E.; Espinós, J. P.; Míguez, H. Origin of LightInduced Photophysical Effects in Organic Metal Halide Perovskites in the Presence of Oxygen. $J$. Phys. Chem. Lett. 2018, 9 (14), 3891-3896.

(27) Fotiou, T.; Triantis, T. M.; Kaloudis, T.; O'Shea, K. E.; Dionysiou, D. D.; Hiskia, A. Assessment of the Roles of Reactive Oxygen Species in the UV and Visible Light Photocatalytic Degradation of Cyanotoxins and Water Taste and Odor Compounds Using $\mathrm{C}_{-} \mathrm{TiO}_{2}$. Water Res. 2016, 90, 52-61.

(28) Pan, X.; Qin, P.; Liu, R.; Li, J.; Zhang, F. Molecular Mechanism on Two Fluoroquinolones Inducing Oxidative Stress: Evidence from Copper/Zinc Superoxide Dismutase. RSC Advances 2016, 6 (94), 91141-91149.

(29) Zabik, N. L.; Anwar, S.; Ziu, I.; Martic-Milne, S. Electrochemical Reactivity of Bulky-Phenols with Superoxide Anion Radical. Electrochim. Acta 2019, 296, 174-180.

(30) Rene, A.; Abasq, M.-L.; Hauchard, D.; Hapiot, P. How Do Phenolic Compounds React toward Superoxide Ion? A Simple Electrochemical Method for Evaluating Antioxidant Capacity. Anal. Chem. 2010, 82, 8703-8710.

(31) Li, X.; Zhang, W.; Cui, W.; Li, J.; Sun, Y.; Jiang, G.; Huang, H.; Zhang, Y.; Dong, F. Reactant Activation and Photocatalysis Mechanisms on Bi-metal@ $\mathrm{Bi}_{2} \mathrm{GeO}_{5}$ with Oxygen Vacancies: A Combined Experimental and Theoretical Investigation. Chem. Eng. J. 2019, 370, 1366-1375.

(32) Vakili, R.; Gholami, R.; Stere, C. E.; Chansai, S.; Chen, H.; Holmes, S. M.; Jiao, Y.; Hardacre, C.; Fan, X. Plasma-Assisted Catalytic Dry Reforming of Methane (DRM) Over MetalOrganic Frameworks (MOFs)-Based Catalysts. Appl. Catal. B: Environ. 2020, 260, 118195. 
(33) Chen, M.; Zou, Y.; Wu, L.; Pan, Q.; Yang, D.; Hu, H.; Tan, Y.; Zhong, Q.; Xu, Y.; Liu, H.; Sun, B.; Zhang, Q. Solvothermal Synthesis of High-Quality All-Inorganic Cesium Lead Halide Perovskite Nanocrystals: From Nanocube to Ultrathin Nanowire. Adv. Funct. Mater. 2017, 27 (23), 1701121.

(34) Eperon, G. E.; Paternò, G. M.; Sutton, R. J.; Zampetti, A.; Haghighirad, A. A.; Cacialli, F.; Snaith, H. J. Inorganic caesium lead iodide perovskite solar cells. J. Mater. Chem. A 2015, 3 (39), 19688-19695.

(35) Hoffman, J. B.; Schleper, A. L.; Kamat, P. V. Transformation of Sintered $\mathrm{CsPbBr}_{3}$ Nanocrystals to Cubic $\mathrm{CsPbI}_{3}$ and $\mathrm{Gradient}_{\mathrm{CsPbBr}} \mathrm{I}_{3-\mathrm{x}}$ through Halide Exchange. J. Am. Chem. Soc. 2016, 138 (27), 8603-8611.

(36) Guhrenz, C.; Benad, A.; Ziegler, C.; Haubold, D.; Gaponik, N.; Eychmüller, A. Solid-State Anion Exchange Reactions for Color Tuning of $\mathrm{CsPbX}_{3}$ Perovskite Nanocrystals. Chem. Mater. 2016, 28 (24), 9033-9040.

(37) Brennan, M. C.; Draguta, S.; Kamat, P. V.; Kuno, M. Light-Induced Anion Phase Segregation in Mixed Halide Perovskites. ACS Energy Lett. 2017, 3 (1), 204-213.

(38) Yoon, S. J.; Kuno, M.; Kamat, P. V. Shift Happens. How Halide Ion Defects Influence Photoinduced Segregation in Mixed Halide Perovskites. ACS Energy Lett. 2017, 2 (7), 1507-1514.

(39) Aristidou, N.; Sanchez-Molina, I.; Chotchuangchutchaval, T.; Brown, M.; Martinez, L.; Rath, T.; Haque, S. A. The Role of Oxygen in the Degradation of Methylammonium Lead Trihalide Perovskite Photoactive Layers. Angew. Chem. 2015, 127 (28), 8326-8330.

(40) Chhillar, P.; Dhamaniya, B. P.; Dutta, V.; Pathak, S. K. Recycling of Perovskite Films: Route toward Cost-Efficient and Environment-Friendly Perovskite Technology. ACS Omega 2019, 4 (7), 11880-11887.

(41) Deepa, M.; Salado, M.; Calio, L.; Kazim, S.; Shivaprasad, S. M.; Ahmad, S. Cesium Power: Low $\mathrm{Cs}^{+}$Levels Impart Stability to Perovskite Solar Cells. Phys. Chem. Chem. Phys. 2017, 19 (5), 4069-4077.

(42) Kumar, M.; Pawar, V.; Jha, P. A.; Gupta, S. K.; Sinha, A. S. K.; Jha, P. K.; Singh, P. ThermoOptical Correlation for Room Temperature Synthesis: Cold-Sintered Lead Halides. J. Mater. Sci.: Mater. Electron. 2019, 30 (6), 6071-6081.

(43) Chang, Y.; Yoon, Y. J.; Li, G.; Xu, E.; Yu, S.; Lu, C.-H.; Wang, Z.; He, Y.; Lin, C. H.; Wagner, B. K.; Tsukruk, V. V.; Kang, Z.; Thadhani, N.; Jiang, Y.; Lin, Z. All-Inorganic Perovskite Nanocrystals with a Stellar Set of Stabilities and Their Use in White Light-Emitting Diodes. ACS Appl. Mater. Interfaces 2018, 10 (43), 37267-37276.

(44) Zu, F.-S.; Amsalem, P.; Salzmann, I.; Wang, R.-B.; Ralaiarisoa, M.; Kowarik, S.; Duhm, S.; Koch, N. Impact of White Light Illumination on the Electronic and Chemical Structures of Mixed Halide and Single Crystal Perovskites. Adv. Opt. Mater. 2017, 5 (9), 1700139.

(45) Rajendra Kumar, G.; Dennyson Savariraj, A.; Karthick, S. N.; Selvam, S.; Balamuralitharan, B.; Kim, H.-J.; Viswanathan, K. K.; Vijaykumar, M.; Prabakar, K. Phase Transition Kinetics and Surface Binding States of Methylammonium Lead Iodide Perovskite. Phys. Chem. Chem. Phys. 2016, 18 (10), 7284-7292.

(46) Sadoughi, G.; Starr, D. E.; Handick, E.; Stranks, S. D.; Gorgoi, M.; Wilks, R. G.; Bär, M.; Snaith, H. J. Observation and Mediation of the Presence of Metallic Lead in Organic-Inorganic Perovskite Films. ACS Appl. Mater. Interfaces 2015, 7 (24), 13440-13444.

(47) Yang, J.; Hong, Q.; Yuan, Z.; Xu, R.; Guo, X.; Xiong, S.; Liu, X.; Braun, S.; Li, Y.; Tang, J.; Duan, C.; Fahlman, M.; Bao, Q. Unraveling Photostability of Mixed Cation Perovskite Films in Extreme Environment. Adv. Opt. Mater. 2018, 6 (20), 1800262.

(48) Kronik, L. Surface Photovoltage Phenomena: Theory, Experiment, and Applications. Surf. Sci. Report. 1999, 37 (1-5), 1-206. 
(49) Liqiang, J.; Xiaojun, S.; Jing, S.; Weimin, C.; Zili, X.; Yaoguo, D.; Honggang, F. Review of Surface Photovoltage Spectra of Nano-sized Semiconductor and its Applications in Heterogeneous Photocatalysis. Sol. Energy Mater. Sol. Cells 2003, 79 (2), 133-151.

(50) Zhao, J.; Nail, B. A.; Holmes, M. A.; Osterloh, F. E. Use of Surface Photovoltage Spectroscopy to Measure Built-in Voltage, Space Charge Layer Width, and Effective Band Gap in CdSe Quantum Dot Films. J. Phys. Chem. Lett. 2016, 7 (17), 3335-3340.

(51) Ciro, J.; Mesa, S.; Montoya, J. F.; Uribe, J. I.; Betancur, R.; Jaramillo, F. Simultaneous Top and Bottom Perovskite Interface Engineering by Fullerene Surface Modification of Titanium Dioxide as Electron Transport Layer. ACS Appl. Mater. Interfaces 2017, 9 (35), 29654-29659.

(52) Li, Z.-J.; Hofman, E.; Li, J.; Davis, A. H.; Tung, C.-H.; Wu, L.-Z.; Zheng, W. Photoelectrochemically Active and Environmentally Stable $\mathrm{CsPbBr} / \mathrm{TiO}_{2}$ Core/Shell Nanocrystals. Adv. Funct. Mater. 2018, 28 (1), 1704288.

(53) Yin, W.-J.; Shi, T.; Yan, Y., Superior Photovoltaic Properties of Lead Halide Perovskites: Insights from First-Principles Theory. J. Phys. Chem. C 2015, 119 (10), 5253-5264.

(54) Park, N.-G.; Grätzel, M.; Miyasaka, T. Organic Inorganic Halide Perovskite Photovoltaics. Springer International Publishing: 2016.

(55) Aristidou, N.; Eames, C.; Sanchez-Molina, I.; Bu, X.; Kosco, J.; Islam, M. S.; Haque, S. A. Fast Oxygen Diffusion and Iodide Defects Mediate Oxygen-Induced Degradation of Perovskite Solar Cells. Nature Communications 2017, 8 (1), 15218.

(56) AIST: Spectral Database for Organic Compounds, S. http://sdbs.db.aist.go.jp/sdbs/cgibin/direct_frame_top.cgi (accessed 07-07-2019).

(57) Quintero-Saumeth, J.; Rincón, D. A.; Doerr, M.; Daza, M. C. Concerted Double Proton-Transfer Electron-Transfer Between Catechol and Superoxide Radical Anion. Phys. Chem. Chem. Phys. 2017, 19 (38), 26179-26190. 
TOC Figure:

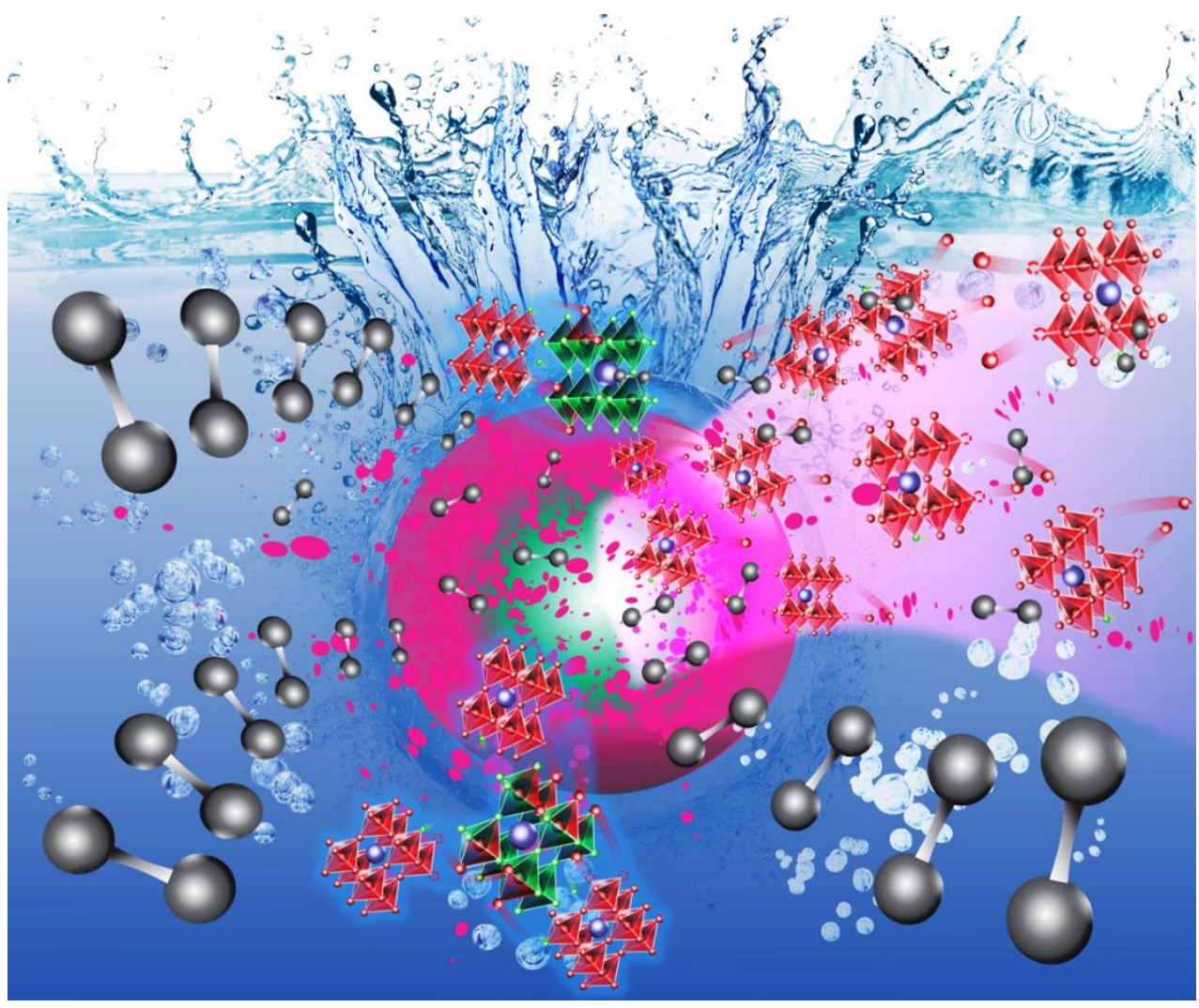

